\title{
NOTIZIE SUI COLLABORATORI DI QUESTO NUMERO
}

Gian ENRICO RusConi insegna Scienza politica presso l'Università di Torino. Tra le sue opere più recenti ricordiamo Giochi e paradossi in politica (1989) e Se cessiamo di essere una nazione (1993).

LEONARDo MoRlino insegna Scienza politica presso l'Università di Firenze. Recentemente ha curato Scienza politica (1989) e Costruire la democrazia (1993).

Josè Ramon Montero insegna Scienza politica presso l'Università autonoma di Madrid ed è condirettore della Fundación Juan March. Autore di numerosi saggi sul comportamento elettorale in Spagna, ha curato Crisis y cambio. Electores y Partidos en la España de los años ochenta (con J. Linz, 1986).

EkKart ZimmermanN insegna Sociologia presso l'Università Tecnica di Dresda. È autore di saggi sulla conflict research e sulle risposte politiche alla Grande Depressione.

ThOmas SAalfeld è professore di Sociologia politica presso l'Università Tecnica di Dresda. Tra le sue opere più recenti: The West German Bundestag (1990) e The Politics of National Populism (1993).

ALDO Di VIRGILIo è ricercatore di Scienza politica presso l'Università della Calabria. E autore di vari saggi e articoli sui sistemi elettorali e sui sistemi partitici. 